\title{
HAEMODYNAMIC CHANGES IN NORMAL PREGNANCY ASSESSED BY ECHOCARDIOGRAPHY
}

\author{
R. Elizabeth Rani1 ${ }^{1}$ B. S. Isaac Ebenezer². \\ 1. Assistant Professor Department of Physiology, Kurnool Medical College, Kurnool. Andhra Pradesh. \\ 2. Professor, Department of Community Medicine, Shantiram Medical College, Nandyal. Andhra Pradesh.
}

\section{CORRESPONDING AUTHOR:}

Dr. B. S. Isaac Ebenezer, 107, A Block, Viswasai Residency, Near Agrigold Office, Kurnool - 518002, Andhra Pradesh.

Email- drisaac.ebenezer@gmail.com

ABSTRACT: A comparative study was done on haemodynamic changes between 60 healthy pregnant women each of whom carried a single foetus and 20 non pregnant healthy women by using echocardiography. Heart rate, blood pressure, cardiac output, ejection fraction, fractional shortening, aortic flow, and pulmonary flow were taken as parameters and compared. The increase of heart rate in pregnant women is highly significant when compared to that of non-pregnant women. The systolic blood pressure and diastolic blood pressure decreased in the $1^{\text {st }} \& 2^{\text {nd }}$ trimesters of pregnancy and the systolic blood pressure returned to non pregnant levels in the $3^{\text {rd }}$ trimester. The cardiac output, ejection fraction, fractional shortening, aortic flow and pulmonary flows were increased in the $1^{\text {st }}, 2^{\text {nd }}$ and $3^{\text {rd }}$ trimesters of pregnancy when compared to non pregnant women.

INTRODUCTION: Pregnancy (Latin word - graviditus) is the carrying of one or more offspring known as fetus (or) embryo inside the uterus of a female human. Pregnancy is a physiological phenomenon which is self limited and is of 38-40 weeks in humans which is divided into 3 trimesters. Pregnancy produces numerous anatomical and physiological changes in the females. The major changes involve the reproductory organs, cardiovascular system, hemopoietic system, respiratory system and excretory system. Many of the maternal changes associated with pregnancy involve the cardiovascular system. The understanding these adaptations to pregnancy is an important applied aspect of physiology.

During normal pregnancy significant vascular and hemodynamic adjustments occur. Pregnancy is associated with volume overload producing alteration in cardiovascular physiology (4). Most important changes occur in the first 8 wks of pregnancy (5). In normal women, the blood volume at or very near term averaged about $40-45 \%$ above their non pregnant levels (6). Pregnancy induced hypervolemia helps to meet the demands of enlarged uterus and protect the mother (10). Maternal blood volume expands more rapidly during 2nd trimester and then at slower rate during 3rd trimester (1). Increase in red cell mass as much as $40 \%$ above pre-pregnant levels (8) and increase of maternal plasma erythropoietin levels which peaks during early 3rd trimester (2) allow the cardiovascular system to meet the increased metabolic demands of pregnancy. 
AIMS \& OBJECTIVES: To study the haemodynamic changes between pregnant women and non pregnant women by using echocardiography.

STUDY DESIGN: Case - control study design.

METHODOLOGY: The study was conducted between Sep.2007 to Aug.2008 with the co-operation of the Department of Gynaecology and the Department of Cardiology of Government General Hospital, Kurnool, A.P. 60 normal healthy pregnant women between 22-25 yrs, i.e., 20 pregnant women with mean age 23yrs and parity 1-3 children from each trimester were selected randomly as study group. 20 normal non-pregnant women between 22-25 yrs with mean age of 23yrs were selected as control group. Both the groups were examined for the parameters like heart rate, cardiac output, ejection fraction, fractional shortening, aortic flow, and pulmonary flow by using echocardiography. The parameters of both the study and control groups were compared. The statistical test used is t-test.

INCLUSION AND EXCLUSION CRITERIA: Normal pregnant woman between 20-25 years without any health problems attending to anti natal clinic and normal non pregnant woman of same age group without any health problems who are attendants to the pregnant women were included in the study.

Pregnant women and non pregnant women suffering with any health problems are excluded from the study.

\section{ETHICAL AND GENERAL GUIDELINES:}

1. Ethical clearance was taken from the ethical committee.

2. Volunteers were explained about the procedure and non invasiveness of this technique.

3. Written consent was taken from the subjects.

4. There was no financial burden on the subjects as the study was conducted in the Cardiology department of Government General Hospital, Kurnool.

RESULTS: The following are the results of the study.

Table showing different parameters in control group and study groups

\begin{tabular}{|c|c|c|c|c|c|c|c|c|c|}
\hline \multirow{2}{*}{ S.No } & \multirow{2}{*}{ Parameter } & \multicolumn{2}{|c|}{ Control } & \multicolumn{2}{|c|}{$1^{\text {st }}$ Trimester } & \multicolumn{2}{|c|}{$2^{\text {nd }}$ Trimester } & \multicolumn{2}{|c|}{$3^{\text {rd }}$ Trimester } \\
\hline & & Mean & S.D & Mean & S.D & Mean & S.D & Mean & S.D \\
\hline 1 & Heart Rate & 79.3 & 8.5 & 91.6 & 8.6 & 93.3 & 7.1 & 97.6 & 5.1 \\
\hline \multirow[t]{3}{*}{2} & Blood Pressure & & & & & & & & \\
\hline & Systolic & 109 & 6.0 & 104 & 3.0 & 62 & 2.0 & 68 & 6.0 \\
\hline & Diastolic & 74 & 5.0 & 62 & 3.0 & 62 & 2.0 & 68 & 6.0 \\
\hline 3 & Cardiac Output (lt/min) & 4.3 & 0.6 & 5.9 & 0.9 & 6.4 & 0.8 & 5.6 & 0.8 \\
\hline 4 & Ejection Fraction (\%) & 66 & 5.0 & 73 & 6.0 & 79 & 4.0 & 74 & 6.0 \\
\hline 5 & Fractional Shortening (\%) & 33 & 3.0 & 38 & 5.0 & 42 & 4.0 & 37 & 5.0 \\
\hline 6 & Aortic Flow (m/sec) & 1.3 & 0.16 & 1.4 & 0.13 & 1.4 & 0.15 & 1.37 & 0.17 \\
\hline 7 & Pulmonary Flow (m/sec) & 1.1 & 0.2 & 1.3 & 0.1 & 1.3 & 0.2 & 1.2 & 0.2 \\
\hline
\end{tabular}




\section{ORIGINAL ARTICLE}

\section{Heart Rate}

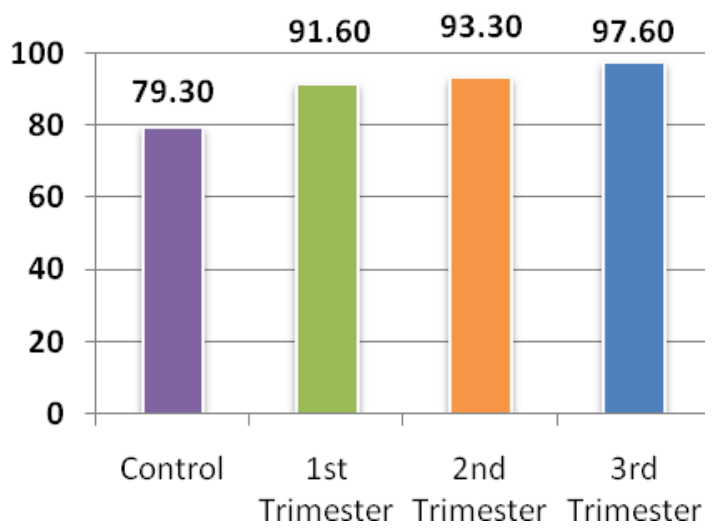

Chart 1: Comparison of heart rate

\section{Diastolic Blood}

\section{Pressure}

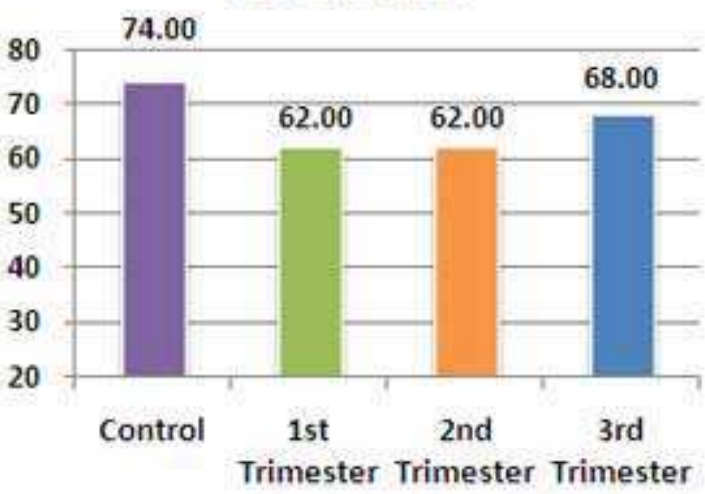

Chart 3: Comparison of Diastolic Blood Pressure

\section{Systolic Blood Pressure}

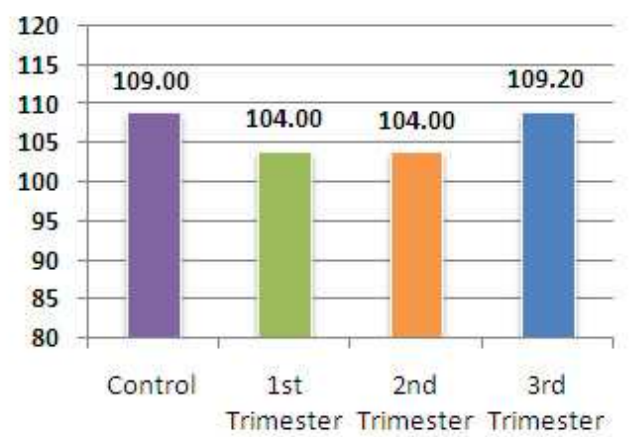

Chart 2 : Comparison of Blood Pressure

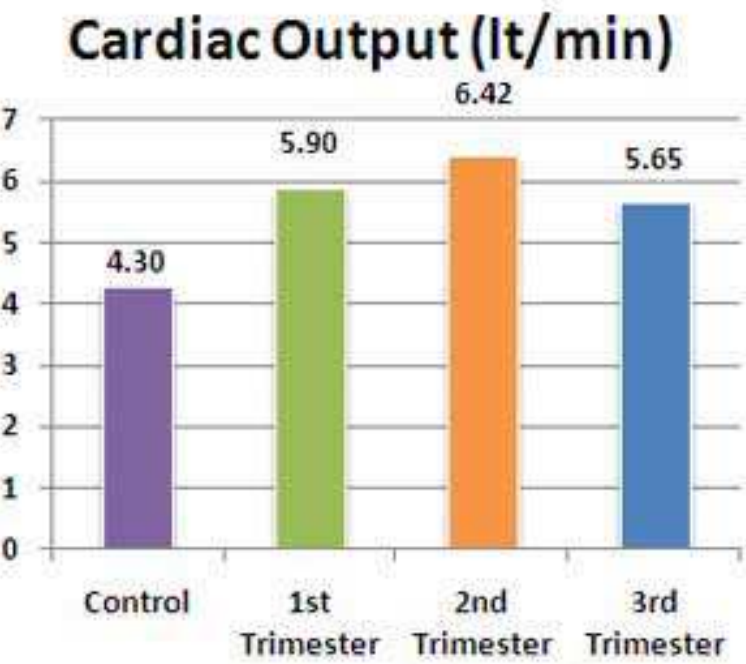

Chart 4 : Comparison of Cardiac Output 


\section{ORIGINAL ARTICLE}

Ejection Fraction (\%)

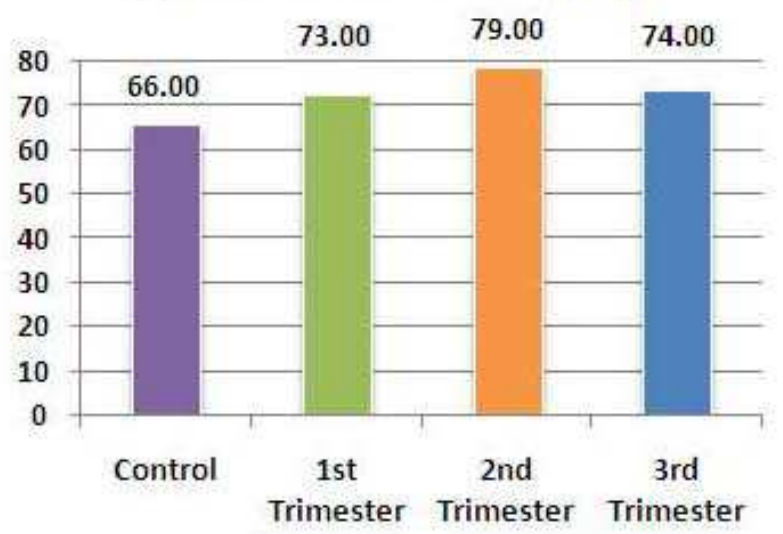

Chart 5: Comparison of Ejection Fraction

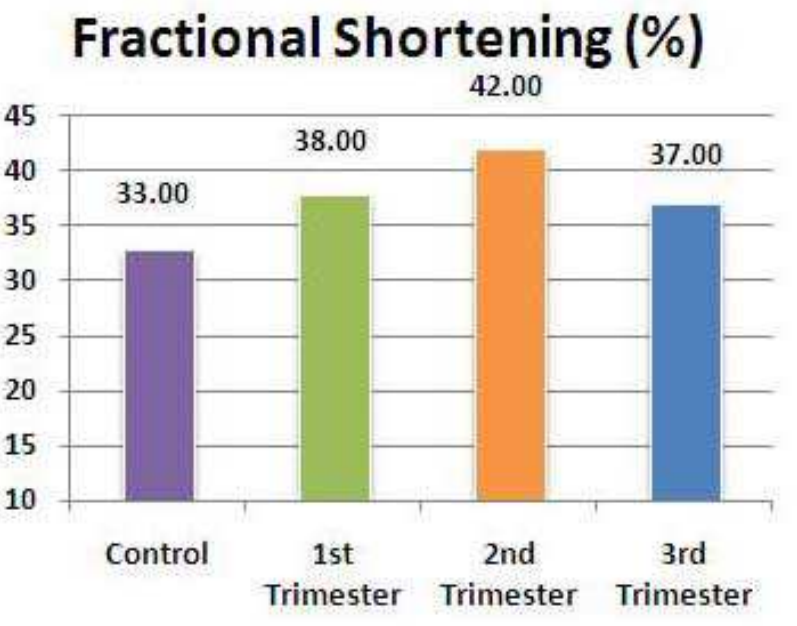

Chart 6: Comparison of Fractional Shortening
Aortic Flow $(\mathrm{m} / \mathrm{sec})$

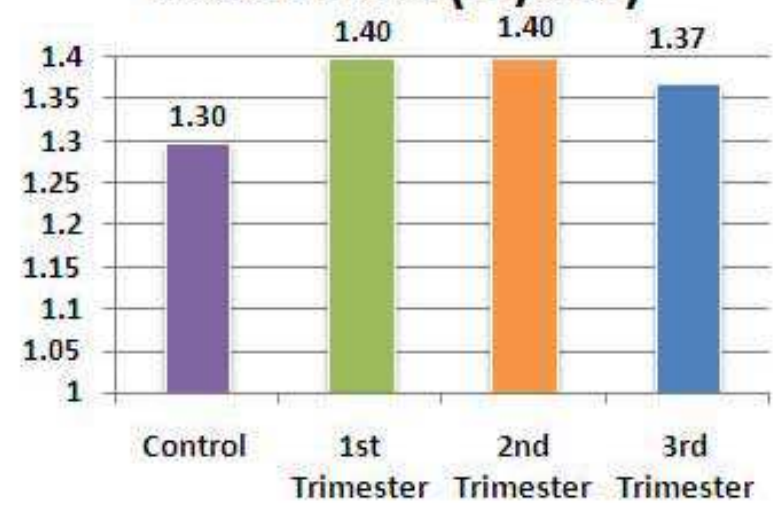

Chart 7: Comparison of aortic Flow
Pulmonary Flow $(\mathrm{m} / \mathrm{sec})$

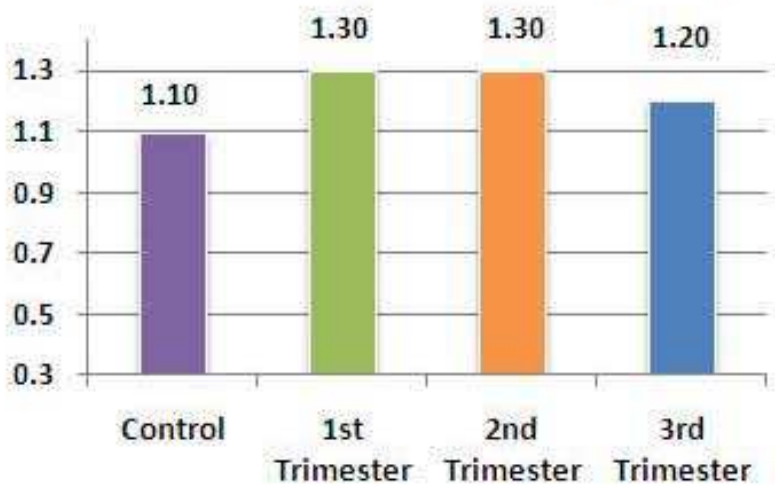

Chart 8: Comparison of Pulmonary flow

DISCUSSION: In my study the heart rate is increased in $1^{\text {st }}$ and $2^{\text {nd }}$ trimesters and a peak rise in $3^{\text {rd }}$ trimester. The difference between control group and study groups is highly significant $(\mathrm{P}<0.001)$. The increase of heart rate in pregnancy is due to increased metabolism to provide the demands of foetus, placenta, increased BMR and oxygen consumption (9) and bain-bridge reflex mechanism (during pregnancy venous return increases, cardiac chambers are distended and initiate cardioacceleratory Bain-Bridge reflex producing increase in heart rate. Pregnancy associated with increase in sympathetic activity because of physiological stress causing increase in heart rate. Wilson (1980) found that the maternal heart rate gets elevated by 12 weeks of gestation, this reaches and stays at $120 \%$ of the base line by 32 weeks of pregnancy.

In the present study the systolic blood pressure is slightly decreased in $1^{\text {st }}$ and $2^{\text {nd }}$ trimesters and return to non pregnant levels in the $3^{\text {rd }}$ trimester. The difference between control group and $1^{\text {st }}, 2^{\text {nd }}$ trimesters of pregnancy is statistically significant. The diastolic blood pressure is decreased in $1^{\text {st }}$ and $2^{\text {nd }}$ trimesters and returned to non-pregnant levels in $3^{\text {rd }}$ trimester. The 
difference between control group and $1^{\text {st }}, 2^{\text {nd }}$ trimesters of pregnancy is highly significant $(\mathrm{P}<0.001)$. The decreased blood pressure in pregnancy is due to decreased vascular resistance as a result of reduction in vascular tone mediated by gestational hormonal activity (3). Prostacyclin is increased in pregnancy and regulates the blood pressure. Renin-angiotensin system is important in the early period of pregnancy blood pressure maintenance. Endothelin 1 plays an important role in maintaining vascular tone in pregnancy. According to Gillivray (1969), both the systolic and diastolic blood pressure decrease until mid pregnancy with gradual recovery to non pregnant values by late gestation (11).

In the present study the cardiac output is increased in all trimesters of pregnancy and is statistically significant $(\mathrm{P}<0.001)$. The increase in cardiac output is due to increase in heart rate. Stroke volume begins to increase in early pregnancy and continue to increase throughout pregnancy (7). Stroke volume increases because of increased end diastolic volume. Cardiac output increased during pregnancy because of higher stroke volume in pregnancy and late increase in heart rate (15).

The major haemodynamic changes induced by pregnancy include an increase in cardiac output, sodium and water retention leading to blood volume expansion and reduction in systemic vascular resistance and systemic blood pressure. Plasma renin activity tends to be increased and atrial natriuretic peptide levels are slightly reduced in pregnancy and thereby rise in vascular capacitance (16). Steward Hunter and Stephen C. Robson reported that cardiac output has increased by 5 weeks after the last menstrual period and the increase continued to 24 weeks, when it was $45 \%$ above the non pregnant level (12).

In the present study, the ejection fraction has increased in all trimesters and mean rate of circumferential fiber shortening increased during pregnancy and this increase occurs during the first 2 trimesters and seems to fall away during the 3rd trimester.

Ejection fraction was 55\% (normal range 50-70\%) In a study conducted by D A Perkins (17). Ejection fraction, fractional shortening were within normal limits in a study conducted by A.K Pandey and A. Das et.al (18). Robson SC, Hunter S. and co workers (1989) stated that several studies of M-mode indices have shown that ejection fraction increase during pregnancy.

In my study fractional shortening increased in all trimesters of pregnancy. Dushyanth K. Desai et al stated that LV fractional shortening during pregnancy is preserved, findings that are similar to data of Robson et al and Mabie et al (14).

In my study, the aortic and pulmonary flow increased in all trimesters of pregnancy and the difference between control group and $1^{\text {st }}, 2^{\text {nd }}$ and $3^{\text {rd }}$ trimesters of pregnancy is statistically significant. : A chronic natural volume overload state strongly influences diastolic filling dynamics (19).

Frank-Starling law states that when increased quantities of blood flows into the heart, the increased blood stretches the walls of the chambers, as a result the cardiac muscle contracts with increased force and this empties the extra blood that has entered from the systemic circulation, thereby increasing the aortic flow and pulmonary flow. Kane A. and colleagues (1997) stated that aortic and pulmonary blood flow rates were higher during pregnancy (13).

CONCLUSIONS AND ITS IMPLICATIONS: In the present study of hemodynamic changes in pregnancy using echocardiography, the heart rate is increased in $1^{\text {st }}$ and $2^{\text {nd }}$ trimesters of 
pregnancy and a peak rise in $3^{\text {rd }}$ trimester than that of normal non pregnant women. The systolic pressure and diastolic pressures are decreased in $1^{\text {st }}$ and $2^{\text {nd }}$ trimesters and return to non pregnant levels in the $3^{\text {rd }}$ trimester. The cardiac output, ejection fraction, fractional shortening, aortic flow and pulmonary flow are increased in all trimesters of pregnancy than that of normal non pregnant women. This study has shown that pregnancy is a physiological volume overload brought about by gestational hormones, and a physiological stress, with increased circulating levels of stress related hormone. The hemodynamic changes that occur during pregnancy allow the cardiovascular system to meet the increased metabolic demands of pregnancy.

Understanding about the hemodynamic changes in normal pregnancy by echocardiography helps in diagnosing pathological conditions of the heart during pregnancy and thereby proper planning in management of cases.

\section{ACKNOWLEDGEMENTS:}

1. Dr. Raja Kumari, Professor \& Head of Physiology, Kurnool Medical College, Kurnool, for her guidance and help.

2. Dr. Chandra Sekhar, Professor \& Head of Cardiology, Government General Hospital, Kurnool, for his help in conduction Echo Cardiography.

3. Dr. Pushpa Latha, Professor \& Head of Obstetrics \& Gynaecology, Government General Hospital, Kurnool, for help in providing subjects.

\section{REFERENCES:}

1. Benstein I M Zeigler w, Badger GJ; plasma volume expansion in early pregnancy. Obstet Gynaecol 97: $669 ; 2001$.

2. Clapp and colleagues 2003; Effect of maternal exercise and feto-placental growth rate on serum erythropoietin concentration, Amj. Obstet Gynaecol 188; 1021, 2003.

3. Hankins GD, Clark SL, UCI Kan E, Van Hook JW Maternal oxygen transport variables during the third trimester of normal pregnancy. Amj. Obstet Gynaecol 1999; 180; 406-409.

4. Hamilton B.E and Thomson K.J. The heart in pregnancy and the child bearing age, Little, Brown and W. Buslin 1941.

5. Mc. Lauglin Mk, In Lindeimer ML,Roberts JM: Cunningam FG Chesleys Hypertensive diseases in pregnancy, $2^{\text {nd }}$ ed. Stanford, CT Appleton and Lange 1999. P. 69

6. Prichard JA; Changes in the blood volume during pregnancy and delivery. Anesthesiology 26; 393, 1965.

7. Robson SC, Hunter S. Boys RJ. Dunlop W. Serial study of factors influencing changes in cardiac output during human pregnancy Am. J, Physiol. 1989; 256 - H 1060 - H 1065.

8. Taylor DJ. Lind T, Red cell mass during and after normal pregnancy Br. J. Obstet. Gynaecol. 1979; 86; $364-70$.

9. Wilson M. Mongauti AA, Zervondeki l et al, Blood pressure, the rennin-aldosterone system and sex steroids throughout normal pregnancy Am J. Med, JAN 1980.68(!) 97 - 107.

10. Whittaker PG Mac Phails, Lind T; Serial hematologic changes and pregnancy outcome. Obstet Gynaecol 88, 33, 1996.

11. Mac Gillivray I, Rose GA, Rowe B, Blood pressure survey in pregnancy .clin. sc. Oct 1969;37(2)395-407. 


\section{ORIGINAL ARTICLE}

12. Steward Hunter, Stephen C Robson. Adaptation of Maternal heart in pregnancy Br. Heart. J 1992 December 68(12) 540-543.

13. Kane A, Bas A, Sarr M. Diop IB ane L, Faye MC; Diocys M, Echocardiographic parameters in normal pregnant women. Ann Cardiol Angeiol (Paris) 1997; 46(1) 21-7

14. Dushyanth K. Desai, MBchB, FCP, Jagidesa Moodley, FRCOG and D. P. Naidu FRCP. Echocardiographic assessment of cardiovascular Hemodynamics in normal pregnancy, Obstetrics \& Gynaecology 2004; 104:28-29

15. Morphological and functional adaptation of the maternal heart during pregnancy, article from Pub.Med.Gov, U.S., National library of medicine, national institute of health,2012 May $1 ; 5(3)$ 289-297

16. Grindheim G. Estensen M E, Langesaeter E, et.al changes in blood pressure during healthy pregnancy, J Hypertens $2012 ; 30342$

17. D A Perkins Nov. 2008, cleaveland clinic journal of medicine vol 75, 788-792

18. Maternal myocardial performance in various stages of pregnancy, A K Pandey,A. Das et.al. 2010, Research journal of cardiology 3; 9-16

19. Left ventricular diastolic function in normal pregnancy, Susan Wilansky, 1999;99: 511517. 